\title{
Determination and Pharmacokinetic Study of Jaceosidin in Rat Plasma by UPLC-MS/MS
}

\author{
Yunfang Zhou ${ }^{1,2}$, Bingbao Chen ${ }^{2}$, Junyan Chen ${ }^{2}$, Yanwen Dong ${ }^{2}$, Shuanghu Wang ${ }^{1}$, Congcong Wen ${ }^{2}$, \\ Xianqin Wang $^{3 *}$ and Xiaomin $\mathbf{Y u}^{4 *}$ \\ ${ }^{1}$ The Laboratory of Clinical Pharmacy, The People's Hospital of Lishui, Lishui 323000, China \\ ${ }^{2}$ Laboratory Animal Centre, Wenzhou Medical University, Wenzhou 325035, China \\ ${ }^{3}$ Analytical and Testing Center, Wenzhou Medical University, Wenzhou 325035, China \\ ${ }^{4}$ School of Pharmaceutical Sciences, Wenzhou Medical University, Wenzhou 325035, China
}

Received: 20 August 2016; accepted: 29 December 2016

\begin{abstract}
In this work, a sensitive and selective ultra-performance liquid chromatography-tandem mass spectrometry (UPLCMS/MS) method was developed and fully validated for determination of jaceosidin in rat plasma. Avicularin was used as the internal standard (IS), and protein precipitation by acetonitrile was used to prepare samples. Chromatographic separation was achieved on a UPLC BEH C18 column $(2.1 \mathrm{~mm} \times 100 \mathrm{~mm}, 1.7 \mu \mathrm{m})$ with $0.1 \%$ formic acid and acetonitrile as the mobile phase with gradient elution. An electrospray ionization (ESI) source was applied and operated in positive ion mode; multiple reaction monitoring (MRM) mode was used for quantification. Calibration plots were linear throughout the range $2-500 \mathrm{ng} \mathrm{mL}^{-1}$ for jaceosidin in rat plasma. Relative standard deviation (RSD) of intra-day and inter-day precision was less than $12 \%$. The accuracy of the method was between $88.7 \%$ and $109.7 \%$. Mean recoveries of jaceosidin in rat plasma ranged from $65.4 \%$ to $77.9 \%$. The developed UPLC-MS/MS method was successfully applied to pharmacokinetic study of jaceosidin after intravenous administration of $2 \mathrm{mg} \mathrm{kg}^{-1}$ in rats. We could find that the jaceosidin rapidly eliminated, the $t_{1 / 2}$ was $0.7 \pm 0.3 \mathrm{~h}$, and clearance (CL) was $22.4 \pm 3.0 \mathrm{~L} \mathrm{~h}^{-1} \mathrm{~kg}^{-1}$.
\end{abstract}

Keywords: Jaceosidin, UPLC-MS/MS, pharmacokinetics, rat plasma

\section{Introduction}

A flavonoid in Artemisia argyi and Eupatorium lindleyanum [1-4], jaceosidin, also was discovered in Paronychia argentea Lam and antileishmanial metabolites from Lantana balansae [5, 6]. Jaceosidin had a good anti-inflammatory effect [7-10] and played a role in immune suppression. Through cell cycle arrest and induction of apoptosis, jaceosidin in many studies and different targets, it was proven to be effective against tumor cells [11-18]. It showed a positive effect in promoting angiogenesis [19] and could be effective triggers of strong induced resistance against both necrotrophic and biotrophic plant pathogens [20].

There was a rapid, sensitive, and selective liquid chromatography-tandem mass spectrometric (LC-MS/MS) method developed for the quantification of jaceosidin in rat plasma to characterize the pharmacokinetics of jaceosidin [21]. Song et al. developed a rapid, sensitive, and selective liquid chromatography-tandem mass spectrometric (LC-MS/MS) method for the quantification of jaceosidin in rat plasma to characterize the pharmacokinetics of jaceosidin. Jaceosidin and linezolid (internal standard, IS) were extracted from plasma samples with ethyl acetate at acidic $\mathrm{pH}$ using the mixture of acetonitrile and $0.1 \%$ formic acid $(45: 55, v / v)$ as a mobile phase. The analytical run time was $3.5 \mathrm{~min}$.

In this paper, an ultra-performance liquid chromatographytandem mass spectrometry (UPLC-MS/MS) method with an electrospray ionization (ESI) source in multiple reaction monitoring (MRM) mode was developed and validated for determination of jaceosidin in rat plasma. This established method exhibited high sensitivity, simple one-step protein precipitation by acetonitrile used for sample preparation, and short run time

* Author for correspondence: lankywang@163.com, yuxiaominwz@163.com
(3.0 min). Afterwards, this method was applied to study the pharmacokinetic behavior of jaceosidin.

\section{Experimental}

Chemicals and Reagents. Jaceosidin (purity, >98\%; Figure 1a) and avicularin (internal standard; purity, $>98 \%$; Figure 1b) were purchased from the Chengdu Mansite Pharmaceutical Co. Ltd. (Chengdu, China). LC-grade acetonitrile and methanol were purchased from Merck Company (Darmstadt, Germany). Ultra-pure water was prepared by Millipore Milli-Q purification system (Bedford, MA, USA). Rat blank plasma samples were supplied by drug-free rats (Laboratory Animal Center of Wenzhou Medical University).

Instrumentation and Conditions. A UPLC-MS/MS system with ACQUITY I-Class UPLC and a Xevo TQD triplequadrupole mass spectrometer (Waters Corp., Milford, MA, USA), equipped with an ESI interface, was used to analyze the compounds. The UPLC system was comprised of a binary solvent manager (BSM) and a sample manager with flowthrough needle (SM-FTN). Masslynx 4.1 software (Waters Corp.) was used for data acquisition and instrument control.

Jaceosidin and avicularin (IS) were separated using a UPLC BEH C18 column $(2.1 \mathrm{~mm} \times 100 \mathrm{~mm}, 1.7 \mu \mathrm{m}$, Waters, USA) maintained at $40{ }^{\circ} \mathrm{C}$. The initial mobile phase consisted of acetonitrile and water (containing $0.1 \%$ formic acid) with gradient elution at a flow rate of $0.4 \mathrm{~mL} \mathrm{~min}^{-1}$ and an injection volume of $2 \mu \mathrm{L}$. Elution was in a linear gradient, where the acetonitrile content increased from $20 \%$ to $40 \%$ between 0 and $1.0 \mathrm{~min}$, and then increased to $85 \%$ at $2.0 \mathrm{~min}$. The acetonitrile content was maintained at $85 \%$ for $0.5 \mathrm{~min}$ and then dropped to $20 \%$ within $0.1 \mathrm{~min}$. The total run time of the analytes was 3 min.

This is an open-access article distributed under the terms of the Creative Commons Attribution-NonCommercial 4.0 International License (https://creativecommons.org/licenses/by-nc/4.0/), which permits unrestricted use, distribution, and reproduction in any medium for non-commercial purposes, provided the original author and source are credited, a link to the CC License is provided, and changes - if any - are indicated. 
<smiles>COc1cc(-c2cc(=O)c3c(O)c(OC)c(O)cc3o2)ccc1O</smiles>

(a)<smiles>O=c1c(O[C@@H]2O[C@H](CO)[C@@H](O)[C@H](O)[C@H]2O)c(-c2ccc(O)c(O)c2)oc2cc(O)cc(O)c12</smiles>

(b)

Figure 1. Chemical structure of jaceosidin (a) and avicularin (IS, b)
Mass spectrometric detection was performed on a triplequadrupole mass spectrometer equipped with an ESI interface in positive mode. Nitrogen was used as the desolvation gas $\left(1000 \mathrm{~L} \mathrm{~h}^{-1}\right)$ and cone gas $\left(50 \mathrm{~L} \mathrm{~h}^{-1}\right)$. Ion monitoring conditions were defined as capillary voltage of $1.5 \mathrm{kV}$, source temperature of $150{ }^{\circ} \mathrm{C}$, and desolvation temperature of $500{ }^{\circ} \mathrm{C}$. MRM modes of $\mathrm{m} / \mathrm{z} 331.3 \rightarrow 316.2$ for jaceosidin and $\mathrm{m} / \mathrm{z}$ $435.0 \rightarrow 303.0$ for IS were utilized to conduct quantitative analysis (Figure 2).

Calibration Standards and Quality Control Samples. The stock solutions of jaceosidin $\left(1.0 \mathrm{mg} \mathrm{mL}{ }^{-1}\right)$ and avicularin (IS) $\left(1.0 \mathrm{mg} \mathrm{mL}^{-1}\right)$ were prepared in methanol-water (50:50). The $0.5 \mu \mathrm{g} \mathrm{mL}^{-1}$ working standard solution of the IS was prepared from the IS stock solution by dilution with methanol; working solutions for calibration and controls were prepared from stock solutions similarly, using methanol diluent. All of the solutions were stored at $4{ }^{\circ} \mathrm{C}$ and were brought to room temperature before use.

Jaceosidin calibration standards were prepared by spiking blank rat plasma with appropriate amounts of the working solutions. Calibration plots were offset to range between 2 and 500 $\mathrm{ng} \mathrm{mL} \mathrm{m}^{-1}$ for jaceosidin in rat plasma at $2,5,10,20,50,100$, 200 , and $500 \mathrm{ng} \mathrm{mL}^{-1}$, each by adding $10 \mu \mathrm{L}$ of the appropriate working solution to $100 \mu \mathrm{L}$ of blank rat plasma, followed by short vortex mixing. Quality-control (QC) samples were prepared in the same manner as the calibration standards, in three different plasma concentrations $\left(4,150\right.$, and $\left.450 \mathrm{ng} \mathrm{mL}^{-1} \mathrm{ng} \mathrm{mL}^{-1}\right)$. The calibration standards and QC samples protein were precipitated by acetonitrile before UPLC-MS/MS analysis.

Sample Extraction. In our work, protein precipitation by acetonitrile was used for extraction jaceosidin from plasma
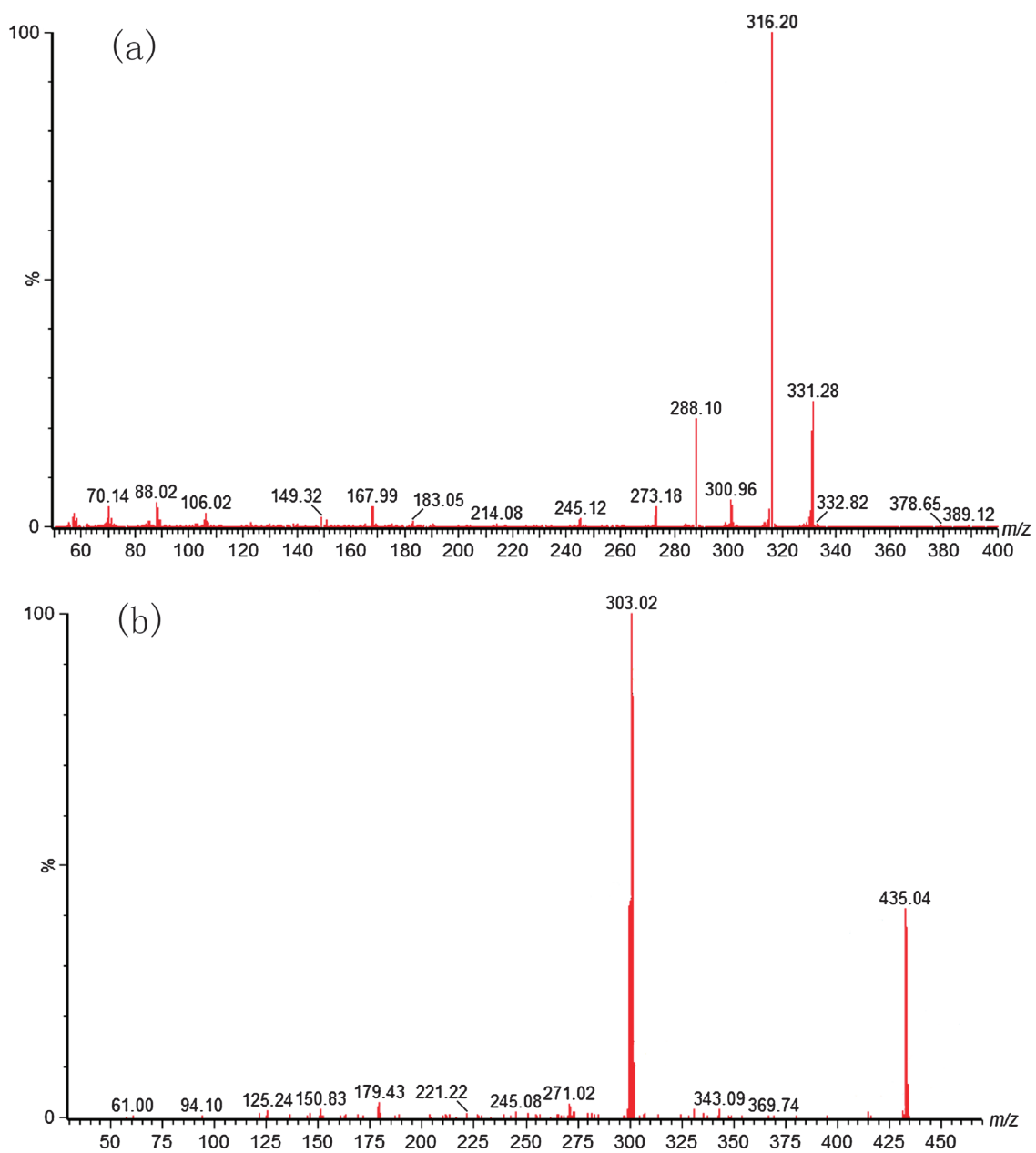

Figure 2. Mass spectrum of jaceosidin (a) and avicularin (IS, b) 
sample. Before analysis, the plasma sample was thawed to room temperature. An aliquot of $10 \mu \mathrm{L}$ of the IS working solution $\left(0.5 \mu \mathrm{g} \mathrm{mL}^{-1}\right)$ was added to $100 \mu \mathrm{L}$ of the collected plasma sample in a $1.5 \mathrm{~mL}$ centrifuge tube, followed by the addition of $200 \mu \mathrm{L}$ of acetonitrile. The tubes were vortex mixed for $1.0 \mathrm{~min}$. After centrifugation at $14,900 \mathrm{~g}$ for $10 \mathrm{~min}$, the supernatant $(2 \mu \mathrm{L})$ was injected into the UPLC-MS/MS system for analysis.

Method Validation. Rigorous tests for selectivity, linearity, accuracy, precision, recovery, and stability, according to the guidelines set by the United States Food and Drug
Administration (FDA) and European Medicines Agency (EMA), were conducted in order to thoroughly validate the proposed bioanalytical method [22-27]. Validation runs were conducted on three consecutive days. Each validation run consisted of one set of calibration standards and six replicates of QC plasma samples [28-32].

The selectivity of the method was evaluated by analyzing blank rat plasma, blank plasma-spiked jaceosidin and IS, and a rat plasma sample.

Calibration curves were constructed by analyzing spiked calibration samples on three separate days. Peak area ratios of
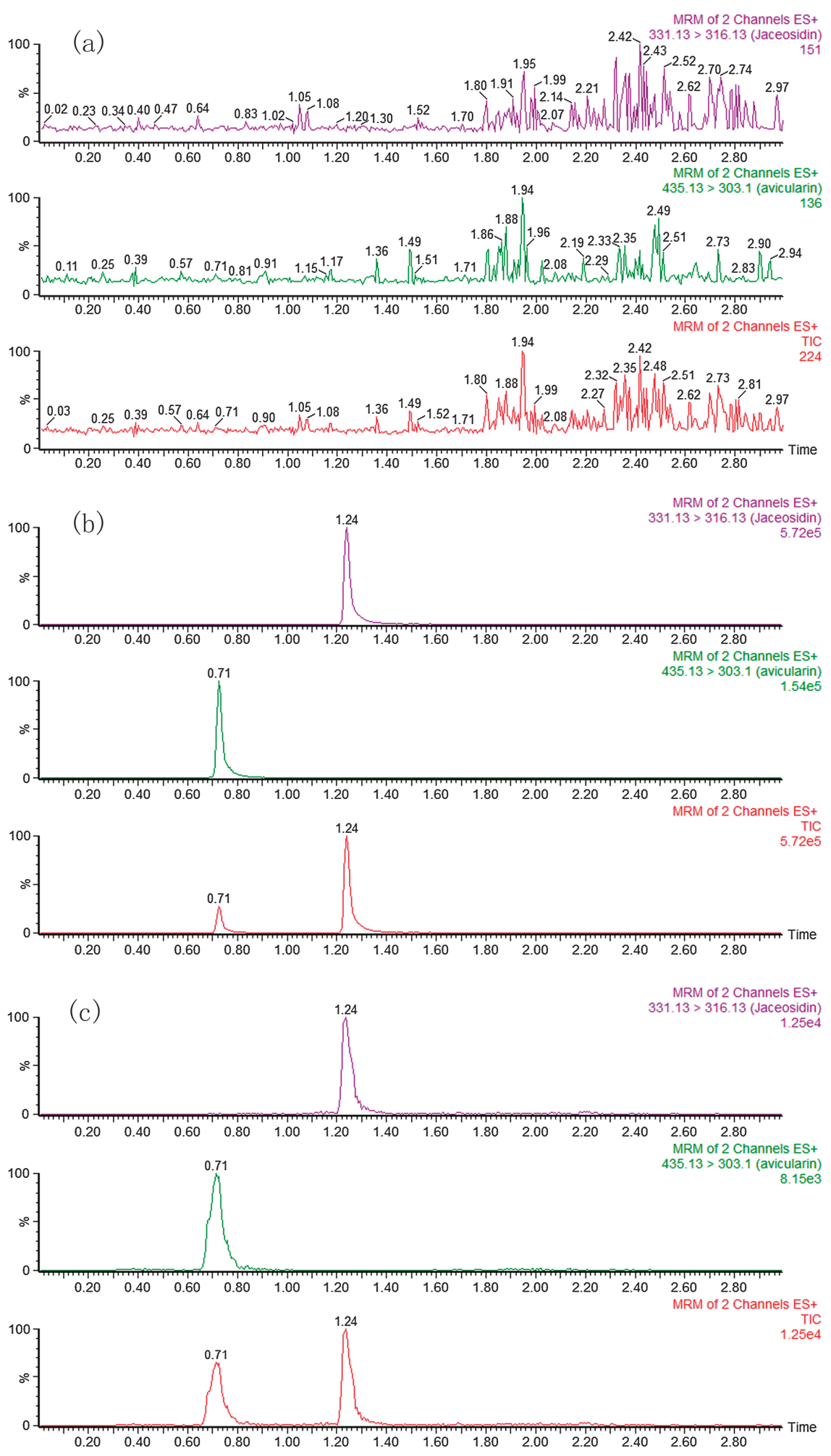

Figure 3. Representative UPLC-MS/MS chromatograms of jaceosidin and avicularin (IS). a, Blank plasma; b, blank plasma spiked with jaceosi$\operatorname{din}\left(2 \mathrm{ng} \mathrm{mL}^{-1}\right)$ and IS $\left(50 \mathrm{ng} \mathrm{mL}^{-1}\right)$; c, a rat plasma sample $0.25 \mathrm{~h}$ after intravenous administration of single dosage $2 \mathrm{mg} \mathrm{kg}^{-1} \mathrm{jaceosidin}$ 
jaceosidin-to-IS were plotted against analyte concentrations. Resultant standard curves were well fitted to the equations by linear regression, with a weighting factor of the reciprocal of the concentration $(1 / x)$ in the concentration range of $2-500 \mathrm{ng} \mathrm{mL}^{-1}$. The lower limit of quantification (LLOQ) was defined as the lowest concentration on the calibration curves.

To evaluate the matrix effect, blank rat plasma was extracted and spiked with the analyte at 4,150 , and $450 \mathrm{ng} \mathrm{mL}^{-1}$ concentrations $(n=6)$. The corresponding peak areas were then compared to those of neat standard solutions at equivalent concentrations; this peak area ratio is defined as the matrix effect. The matrix effect of the IS was evaluated at a concentration of $50 \mathrm{ng} \mathrm{mL}^{-1}$ in a similar manner.

Accuracy and precision were assessed by the determination of QC samples at three concentration levels in six replicates (4, 150 , and $450 \mathrm{ng} \mathrm{mL}^{-1}$ ) over 3 days of validation testing. The precision is expressed as relative standard deviation (RSD).

The recovery of jaceosidin was evaluated by comparing the peak area of extracted QC samples with those of reference QC solutions reconstituted in blank plasma extracts $(n=6)$. The recovery of the IS was determined in the same way.

Carry-over was assessed following injection of a blank plasma sample immediately after 3 repeats of the upper limit of quantification (ULOQ), after which the response was checked for accuracy [33-35].

Stability values of jaceosidin in rat plasma were evaluated by analyzing three replicates of plasma samples at concentrations of 4 or $450 \mathrm{ng} \mathrm{mL}^{-1}$ which were all exposed to different conditions. These results were compared with the freshly prepared plasma samples. Short-term stability was determined after the exposure of the spiked samples to room temperature for $2 \mathrm{~h}$ and the ready-toinject samples (after protein precipitation) in the UPLC autosampler at room temperature for $24 \mathrm{~h}$. Freeze-thaw stability was evaluated after three complete freeze-thaw cycles $\left(-20\right.$ to $\left.25^{\circ} \mathrm{C}\right)$ on consecutive days. Long-term stability was assessed after storage of the standard spiked plasma samples at $-20{ }^{\circ} \mathrm{C}$ for 20 days. The stability of the IS $\left(50 \mathrm{ng} \mathrm{mL}^{-1}\right)$ was evaluated similarly [36].

Pharmacokinetic Study. Male Sprague-Dawley rats (200$220 \mathrm{~g}$ ) were obtained from the Laboratory Animal Center of Wenzhou Medical University to study the pharmacokinetics of jaceosidin. All six rats were housed at the Laboratory Animal Center of Wenzhou Medical University. All experimental procedures and protocols were reviewed and approved by the Animal Care and Use Committee of Wenzhou Medical University and were in accordance with the Guide for the Care and Use of Laboratory Animals. Diet was prohibited for $12 \mathrm{~h}$ before the experiment, but water was freely available. Blood samples $(0.3 \mathrm{~mL})$ were collected from the tail vein into heparinized $1.5 \mathrm{~mL}$ polythene tubes at $0.0333,0.15,0.5,1,1.5$, 2 , and $3 \mathrm{~h}$ after intravenous $\left(2 \mathrm{mg} \mathrm{kg}^{-1}\right)$ administration of jaceosidin. The samples were immediately centrifuged at $3000 \mathrm{~g}$ for $10 \mathrm{~min}$. The plasma as obtained $(100 \mu \mathrm{L})$ was stored at $-20{ }^{\circ} \mathrm{C}$ until analysis.

Plasma jaceosidin concentration versus time data for each rat was analyzed by DAS (Drug and Statistics) software (version 2.0, Wenzhou Medical University). The maximum plasma concentration $\left(C_{\max }\right)$ was observed directly from the concentrationtime curve. The area under the plasma concentration-time curve (AUC) was estimated by the trapezoidal rule. The plasma clearance (CL), apparent volume of distribution $(V)$, mean residence time (MRT), and the half-life $\left(t_{1 / 2}\right)$ were estimated using noncompartmental calculations performed with DAS software.

\section{Results and Discussion}

Selectivity and Matrix Effect. Figure 3 shows typical chromatograms of a blank plasma sample, a blank plasma sample spiked with jaceosidin and IS, and a plasma sample. There were no interfering endogenous substances observed at the retention time of the jaceosidin and IS.

The matrix effect for jaceosidin at concentrations of 4,150 , and $450 \mathrm{ng} \mathrm{mL}^{-1}$ was measured between $102.3 \%$ and $106.2 \%$ $(n=6)$. The matrix effect for IS $\left(50 \mathrm{ng} \mathrm{mL} \mathrm{mL}^{-1}\right)$ was $101.1 \%$ $(n=6)$. As a result, matrix effect from plasma is considered negligible in this method.

Calibration Curve and Sensitivity. Linear regressions of the peak area ratios versus concentrations were fitted over the

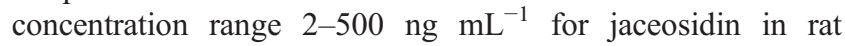
plasma. The equation used to express the calibration curve is $y=0.00204 * x+0.0245, r=0.9991$, where $y$ represents the ratios of jaceosidin peak area to that of IS and $x$ represents the plasma concentration. The LLOQ for the determination of

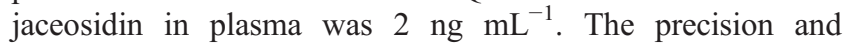
accuracy at LLOQ were $12.5 \%$ and $95.3 \%$, respectively. The LOD, defined as a signal/noise ratio of 3 , was $0.5 \mathrm{ng} \mathrm{mL}^{-1}$ for jaceosidin in rat plasma.

Precision, Accuracy, and Recovery. The precision of the method was determined by calculating RSD for QCs at three concentration levels over 3 days of validation tests. Intra-day precision was $12 \%$ or less, and inter-day precision was $9 \%$ or less at each QC level. The accuracy of the method was between $88.7 \%$ and $109.7 \%$ at each QC level. Mean recoveries of jaceosidin in rat plasma ranged from $65.4 \%$ to $77.9 \%$. The recovery of the IS $\left(50 \mathrm{ng} \mathrm{mL}^{-1}\right.$ ) was $83.6 \%$. The data were shown in Table 1.

Carry-over. None of the analytes showed any significant peak ( $\geq 20 \%$ of the LLOQ and $5 \%$ of the IS) in blank samples injected after the ULOQ samples. Adding 0.4 extra minutes to the end of the gradient elution effectively washed the system between samples, thereby eliminating carry-over [33].

Stability. Results from the autosampler showed that the analyte was stable under room temperature, freeze-thaw, and long-term (20 days) conditions, which was confirmed because the bias in concentrations was within $\pm 13 \%$ of their nominal values. To this effect, the established method is suitable for pharmacokinetic study.

Application. The method exhibited simpler one-step protein precipitation by acetonitrile used for sample preparation and shorter run time $(3.0 \mathrm{~min})$, and more appropriate internal standard was used, compared to that of the literature [21]. The method was applied to a pharmacokinetic study in rats. The mean plasma concentration-time curve after intravenous $\left(2 \mathrm{mg} \mathrm{kg}^{-1}\right)$ administration of jaceosidin was shown in Figure 4. The pharmacokinetic parameters, based on non-compartment model analysis, were summarized in Table 2 . We could find that the jaceosidin rapidly eliminated, the $t_{1 / 2}$ was $0.68 \pm 0.32 \mathrm{~h}$, and CL was $22.35 \pm 3.03 \mathrm{~L} \mathrm{~h}^{-1} \mathrm{~kg}^{-1}$, while jaceosidin exhibited a high systemic clearance $\left(\mathrm{CL}=13.19 \pm 5.08 \mathrm{~L} \mathrm{~h}^{-1} \mathrm{~kg}^{-1}\right)$ and the short terminal elimination half-life $\left(t_{1 / 2}=0.60 \pm 0.20 \mathrm{~h}\right)$ in the literature [21].

\section{Conclusion}

In the present study, a simple, precise, and accurate UPLCMS/MS method for the quantitation of jaceosidin in rat plasma was established, using $100 \mu \mathrm{L}$ of plasma with an LLOQ of

Table 1. Precision, accuracy, and recovery for jaceosidin of QC sample in rat plasma $(n=6)$

\begin{tabular}{lcccccc}
\hline $\begin{array}{l}\text { Concentration } \\
\left(\mathrm{ng} \mathrm{mL} \mathrm{mL}^{-1}\right)\end{array}$ & \multicolumn{2}{c}{ Precision $(\mathrm{CV} \%)$} & & \multicolumn{2}{c}{ Accuracy $(\%)$} & Recovery \\
\cline { 2 - 3 } & Intra-day & Inter-day & & Intra-day & Inter-day & \\
\hline 5 & 11.1 & 8.5 & & 107.4 & 101.9 & 68.2 \\
150 & 8.7 & 10.9 & & 93.3 & 88.7 & 77.9 \\
450 & 5.2 & 6.7 & & 98.9 & 109.7 & 65.4 \\
\hline
\end{tabular}






Figure 4. Mean plasma concentration time profile after intravenous $\left(2 \mathrm{~m} \mathrm{~kg}^{-1}\right)$ administration of jaceosidin in rats

Table 2. Main pharmacokinetic parameters after intravenous administration of jaceosidin in rats $(n=6)$

\begin{tabular}{|c|c|c|c|}
\hline \multirow[t]{2}{*}{ Parameters } & \multirow[t]{2}{*}{ Unit } & Mean & $\mathrm{SD}$ \\
\hline & & \multicolumn{2}{|c|}{ iv $2 \mathrm{mg} \mathrm{kg}^{-1}$} \\
\hline$\overline{\mathrm{AUC}_{(0-t)}}$ & $\mathrm{ng} \mathrm{mL^{-1 } * \mathrm { h }}$ & 87.98 & 9.95 \\
\hline $\operatorname{AUC}_{(0-\infty)}$ & $\mathrm{ng} \mathrm{mL}^{-1} * \mathrm{~h}$ & 90.74 & 12.42 \\
\hline $\operatorname{MRT}_{(0-t)}$ & $\mathrm{H}$ & 0.61 & 0.16 \\
\hline $\operatorname{MRT}_{(0-\infty)}$ & $\mathrm{H}$ & 0.71 & 0.18 \\
\hline$t_{1 / 2}$ & $\mathrm{H}$ & 0.68 & 0.32 \\
\hline CL & $\mathrm{L} \mathrm{h}^{-1} \mathrm{~kg}^{-1}$ & 22.35 & 3.03 \\
\hline$V$ & $\mathrm{~L} \mathrm{~kg}^{-1}$ & 21.01 & 7.42 \\
\hline$C_{\max }$ & $\mathrm{ng} \mathrm{mL} \mathrm{m}^{-1}$ & 243.56 & 84.25 \\
\hline
\end{tabular}

$2 \mathrm{ng} \mathrm{mL}{ }^{-1}$, and the simple protein precipitation by acetonitrile was used to prepare samples. The UPLC-MS/MS method was successfully applied to a pharmacokinetic study of jaceosidin after intravenous administration.

\section{References}

1. Lao, A.; Fujimoto, Y.; Tatsuno, T. J. Pharm. Soc. Jpn. 1983, 103 , 696-699.

2. Sadhu, S. K.; Hirata, K.; Li, X.; Ohtsuki, T.; Koyano, T.; Preeprame, S.; Kowithayakorn, T.; Ishibashi, M. J. Nat. Med. 2006, 60, 325-328.

3. Tan R.; Jia, Z. Planta Med. 1992, 58, 370-372.

4. Vega, M. R. G.; Carvalho, M. G. D.; Vieira, I. J. C.; Braz-Filho, R. J Nat. Med. 2008, 62, 122-123.

5. Maldonado, E. M.; Salamanca, E.; Giménez, A.; Sterner, O.; Maldonado, E. M.; Salamanca, E.; Giménez, A.; Sterner, O. Rev. Bras. Farmacogn. 2016, 26, $180-183$.
6. Sait, S.; Hamri-Zeghichi, S.; Boulekbache-Makhlouf, L.; Madani, K.; Rigou, P.; Brighenti, V.; Prencipe, F. P.; Benvenuti, S.; Pellati, F. J. Pharm. Biomed. Anal. 2015, 111, 231-240.

7. Nam, Y.; Choi, M.; Hwang, H.; Lee, M. G.; Kwon, B. M.; Lee, W. H.; Suk, K. Phytother. Res. 2013, 27, 404-411.

8. Kim, M. J.; Han, J. M.; Jin, Y. Y.; Baek, N. I.; Bang, M. H.; Chung, H. G.; Choi, M. S.; Lee, K. T.; Sok, D. E.; Jeong, T. S. Arch. Pharmacal. Res. 2008, 31 , $429-437$.

9. Min S. W.; Kim NJBaek, N. I. J. Ethnopharmacol. 2009, 125, 497-500.

10. Yin, Y.; Sun, Y.; Gu, L.; Zheng, W.; Gong, F.; Wu, X.; Shen, Y.; Xu,

Q. Eur. J. Pharmacol. 2011, 651, 205-211.

11. Jeong, M. A.; Won, L. K.; Do-Young, Y.; Joo, L. H. Ann. N. Y. Acad. Sci. 2007, 1095, 458-466.

12. Khan, M.; Rasul, A.; Yi, F.; Zhong, L.; Ma, T. Asian Pac. J. Cancer Prev. 2011, 12, 3235-3238.

13. Khan, M.; Yu, B.; Rasul, A.; Al, S. A.; Yi, F.; Yang, H.; Ma, T. J. Evidence-Based Complementary Altern. Med. 2011, 2012, 72-79.

14. Lee, H. G.; Yu, K. A.; Oh, W. K.; Baeg, T. W.; Oh, H. C.; Ahn, J. S.; Jang, W. C.; Kim, J. W.; Lim, J. S.; Choe, Y. K. J. Ethnopharmacol. 2005, 98, 339-343. 15. Lee, J. G.; Kim, J. H.; Ahn, J. H.; Lee, K. T.; Baek, N. I.; Choi, J. H. Food Chem. Toxicol. 2013, 55, 214-221.

16. Li, Y.; Yang, L.; Zhao, Y.; Li, B.; Sun, L.; Luo, H. Bangladesh J. Pharmacol. 2013, 8, 1808-1812.

17. Lv, W.; Sheng, X.; Chen, T.; Xu, Q.; Xie, X. J. Biomed. Biotechnol. 2008, 2008, 394802 .

18. Min-Jung, K.; Do-Hee, K; Won, L. K.; Do-Young, Y.; Young-Joon, S. Ann. N. Y. Acad. Sci. 2007, 1095, 483-495.

19. Lee, T. H.; Jung, H.; Park, K. H.; Bang, M. H.; Baek, N. I.; Kim, J. Exp. Biol. Med. 2014, 239, 1325-1334.

20. Song, G. C.; Ryu, S. Y.; Kim, Y. S.; Lee, J. Y.; Choi, J. S.; Ryu, C. M. Molecules 2013, 18, 12877-12895.

21. Song, W. Y.; Kim, N. J.; Kim, S. Y.; Lee, H. S. J. Pharm. Biomed. Anal. 2009, 49, 381-386.

22. Wang, S.; Wu, H.; Geng, P.; Lin, Y.; Liu, Z.; Zhang, L.; Ma, J.; Zhou,

Y.; Wang, X.; Wen, C. Biomed. Chromatogr. 2016, 30, 1145-1149.

23. Wen, C.; Wang, S. Huang, X.; Liu, Z.; Lin, Y.; Yang, S.; Ma, J.; Zhou,

Y.; Wang, X. Biomed. Chromatogr. 2015, 29, 1805-1810.

24. Wang, X.; Wang, S.; Ma, J.; Ye, T.; Lu, M.; Fan, M.; Deng, M.; Hu, L.; Gao, Z. J. Pharm. Biomed. Anal. 2015, 115, 368-374.

25. Lin, Y. Y.; Geng, P. W.; Gan, Y. F.; Yang, S. P.; Liu, Z. Z.; Xu, M. Z.; Wen, C. C.; Lin, X. X. Lat. Am. J. Pharm. 2016 35, 166-171.

26. Chen, H.; Xia, X.; Li, L. J.; Jiang, W. B.; Wang, Y.; Xia, H. X.; Wang, Z. Y.; Wang, Y. L. Lat. Am. J. Pharm. 2016, 35, 233-238.

27. Wen, C.; Zhang, Q.; He, Y.; Deng, M.; Wang, X.; Ma, J. Acta Chromatogr. 2015, 1, 1-11.

28. Xu, Y.; Bao, S.; Tian, W.; Wen, C.; Hu, L.; Lin, C. Int. J. Clin. Exp. Med. 2015, 8, 17612-17622.

29. Tian, W.; Cai, J.; Xu, Y.; Luo, X.; Zhang, J.; Zhang, Z.; Zhang, Q.; Wang, X.; Hu, L.; Lin, G. Int. J. Clin. Exp. Med. 2015, 8, 15164-15172.

30. Wang, X.; Wang, S.; Lin, F.; Zhang, Q.; Chen, H.; Wang, X.; Wen, C.; Ma, J.; Hu, L. J. Chromatogr. B Anal. Technol. Biomed. Life Sci. 2015, 983 $984,125-131$

31. Wang, S.; Wu, H.; Huang, X.; Geng, P.; Wen, C.; Ma, J.; Zhou, Y.; Wang, X. J. Chromatogr. B Anal. Technol. Biomed. Life Sci. 2015 990, 118-124.

32. Zhang, Q.; Wen, C.; Xiang, Z.; Ma, J.; Wang, X. J. Pharm Biomed Anal. 2014, 90, 134-138.

33. Williams, J. S.; Donahue, S. H.; Gao, H.; Brummel, C. L. Bioanalysis 2012, 4, 1025-1037.

34. Yang, Y.; Liu, C.; Zhang, Y.; Zhou, L.; Zhong, D.; Chen, X. J. Pharm. Biomed. Anal. 2015, 114, 408-415.

35. Deng, P.; Ji, C.; Dai, X.; Zhong, D.; Ding, L.; Chen, X. J. Chromatogr. B Anal. Technol. Biomed. Life Sci. 2015, 989, 71-79.

36. Ma, J.; Wang, S.; Huang, X.; Geng, P.; Wen, C.; Zhou, Y.; Yu, L.; Wang, X. J. Pharm. Biomed. Anal. 2015, 111, 131-137. 